\title{
Justifying the culture of justification
}

Abstract: The ideas of the culture of justification - according to which it is the role of the courts to ensure that every act of the state that affects a person is substantively justifiable - and the related right to justification - which claims that every person possesses a moral and, ideally, constitutional right to the justification that the culture of justification recommends - are intuitively powerful and widely discussed ideas in public law scholarship, but their moral foundation is not yet well understood. This paper presents the moral case for these two concepts which centres on the status of every person as a justificatory agent. It argues that under conditions of reasonable disagreement in politics, this status requires that any law or act be justified not only procedurally (for example, in terms of a democratic vote) but also substantively, and it further demonstrates the necessity of the judicial protection of the right to justification as a matter of principle.

Keywords: culture of justification, right to justification, reasonable disagreement, judicial review, right to a hearing

\section{Introduction}

The culture of justification and its slightly less well known sibling, the right to justification, are intuitively powerful concepts that are widely discussed in current public law scholarship, but their moral foundation is not yet well understood. What we do know is what the two terms broadly mean: in a culture of justification it is the role of the courts to ensure that every act of the state that affects a person is substantively justifiable to him or her; thus, to a considerable extent the government derives its legitimacy from the substantive justifiability of its actions, as opposed to considerations relating exclusively or primarily to, in particular, its democratic credentials. The right to justification expresses the same idea in moral terms; it insists that every citizen has a moral and, ideally, constitutional right to the kind of justification envisaged by the culture of justification.

Furthermore, it is reasonably clear how the idea of a culture of justification operates in practice. The constitutional structure of states that are considered to have a culture of justification - countries that are mentioned in this context include Germany (as the paradigmatic example), the U.K. and other European countries, Canada, South Africa, and Israel $^{1}$ - tends to display a number of features. According to Moshe Cohen-Eliya and Iddo Porat these include the relative absence of legal 'black holes' (implying the reviewability of

\footnotetext{
${ }^{1}$ Moshe Cohen-Eliya and Iddo Porat, Proportionality and Constitutional Culture (Cambridge University Press, 2013), 7. Cohen-Eliya and Porat contrast a culture of justification with a culture of authority, which in their view is the dominant legal culture in the U.S. I do not express a view in this paper with regard to the proper classification of U.S. legal culture.
} 
all governmental actions), ${ }^{2}$ a broad scope of rights (which enables the comprehensive review powers of the constitutional court because every interference with a right triggers the duty of justification), ${ }^{3}$ the use of the doctrines of balancing and proportionality in order to assess the justifiability of an act, ${ }^{4}$ and a comparatively small role for the constitutional text (favouring an assessment of the substantive justifiability of an act without being constrained by the text of the constitution). ${ }^{5}$

Thus, the meaning of the idea of a culture of justification is reasonably clear, and we know how it plays out in the constitutional life of a number of liberal democracies. However, as mentioned above, the question that is largely unresolved is about the moral appeal of the concept. Why, if at all, should we favour a culture of justification (and the right to justification) over other constitutional arrangements? This is the topic addressed by this essay.

It proceeds in the following way. The next section provides a brief overview of the history of the concept and the scholarship on it. The third section moves towards the question of its moral appeal. It considers Rainer Forst's idea of human rights as flowing from a basic right to justification and Mattias Kumm's work on the right to justification as a condition of democracy, concluding that both authors stop short of providing a comprehensive moral case for the culture of justification and the corresponding right to justification. The fourth section builds on their work and presents an account of the moral foundation of the two concepts. I argue that Forst's view of the person as a justificatory agent should be regarded as every person's basic constitutional status. But, as Dimitrios Kyritsis has recently pointed out, it does not follow without further argument that the justification that every person is entitled to must be substantive (as the culture of justification would have it) as opposed to a procedural (in particular, democratic voting). I identify the notion of reasonable disagreement as the key to the resolution of this issue and show that if we acknowledge the centrality of reasonable disagreement in politics, we are indeed forced to accept that every person has a fundamental moral right to the substantive justification that the culture of justification insists on. This leads to the institutional question of whether the constitution should recognise a comprehensive constitutional right to justification that mirrors the moral right, or whether considerations relating, in particular, to the institutional competence of courts speak in favour of a more limited role for them. I show that an outcome-oriented approach to the question of institutional design is inappropriate and that the view of the person as a justificatory being that underlies the culture of justification requires the existence of the judicial protection of the right to justification as a matter of principle.

\footnotetext{
2 Ibid., 113-117.

${ }^{3}$ Ibid., 118-119.

${ }^{4}$ Ibid., passim and in particular ch. 6.

${ }^{5}$ Ibid., 119-120.
} 


\section{The culture of justification}

The term 'culture of justification' was coined by the South African public law scholar Etienne Mureinik, who famously claimed with regard to the point of the Interim Constitution 1993 and in particular its Bill of Rights:

'If the new Constitution is a bridge away from a culture of authority, it is clear what it must be a bridge to. It must lead to a culture of justification - a culture in which every exercise of power is expected to be justified; in which the leadership given by government rests on the cogency of the case offered in defence of its decisions ...

If the Constitution is to be a bridge in this direction, it is plain that the Bill of Rights must be its chief strut. A Bill of Rights is a compendium of values empowering citizens affected by laws or decisions to demand justification. If it is ineffective in requiring governors to account to people governed by their decisions, the remainder of the Constitution is unlikely to be very successful. The point of the Bill of Rights is consequently to spearhead the effort to bring about a culture of justification.' ${ }^{\prime}$

This statement is remarkable and, indeed, radical, but the full extent of its radical nature can easily be overlooked. Mureinik makes four striking points, which I will explain by contrasting them with a more conventional approach. First, he stresses that 'every' exercise of power must be justified and that the Bill of Rights empowers citizens to demand justifications whenever they are 'affected' by laws or decisions. This gives an extraordinary scope to the duty of justification. A more conventional view might hold that citizens can demand justifications whenever their 'fundamental rights' have been limited; and here 'fundamental rights' would refer to a limited number of specific rights, such as the rights of the South African constitution or the European Convention on Human Rights. This more conventional picture is however not Mureinik's; he assumes a comprehensive duty of justification. And while the Bill of Rights is relevant in this context, it is only the tool used to bring about a culture of justification, not its source: the Bill of Rights must be interpreted so that it can serve what Mureinik identifies as its purpose, namely to bring about a culture of justification. ${ }^{7}$

Second, the kind of justification that Mureinik has in mind is substantive and to be determined by moral argument, not by recourse to procedural or legal/constitutional values. Thus, for him every exercise of public power should be justifiable in the sense of what we may call 'being supported by strong enough substantive reasons'. This contrasts with a more conventional approach to justification which might hold that the justification of a law consists in its having been passed in line with certain procedures (for example, by a democratically elected legislature) or in line with the values or rights set out in the text of the

\footnotetext{
${ }^{6}$ Etinenne Mureinik, 'A Bridge to Where? Introducing the Interim Bill of Rights', 10 (1994) South African Journal on Human Rights 31, 32 (footnotes omitted). See further David Dyzenhaus, 'Law as Justification: Etienne Mureinik's Conception of Legal Culture', 14 (1998) South African Journal of Human Rights 11.

${ }^{7}$ Mureinik does not, however, address the obvious follow-up question of whether the bill of rights should be interpreted to include a general right to liberty, meaning that indeed any act that affects someone is considered to limit a right and trigger the duty of justification. I will return to this point further below.
} 
constitution. Mureinik is not interested in these latter kinds of justification but rather demands a substantive one.

Third, since the bill of rights of the constitution is the 'chief strut' of the culture of justification, it follows that the primary responsibility for bringing it about lies with the courts, and ultimately the constitutional court. The culture of justification is therefore not simply, as a more conventional proponent might claim, a desirable state of affairs which should be promoted by various actors - say, the media in challenging official policy, the citizens by being alert and politically active, the legislature by debating carefully and conscientiously new legislation. For Mureinik, the primary responsibility lies with the courts in general and the constitutional court in particular.

Fourth and finally, the project of bringing about a culture of justification is of crucial importance: if it fails, Mureinik warns, 'the remainder of the Constitution is unlikely to be very successful'. Thus, the culture of justification is not simply, as a more conventional view might hold, 'nice to have'. Rather, it is fundamental: it is the basis without the South African experiment of setting up an inclusive, liberal democracy cannot fully succeed.

We can now summarise the idea of a culture of justification as insisting that citizens can rely on the bill of rights to challenge any act by the state which affects them; and that the courts, and in the final instance the constitutional court, have the responsibility of establishing whether the act in question is substantively justifiable. Mureinik wrote his paper with a view to a particular moment in the history of a particular country and did not draw on wider debates in constitutional theory; furthermore, he died shortly after its publication. Thus, we cannot know whether he intended the culture of justification to be as radical as his words indicate; nor can we know whether he would have recommended the culture of justification as a general model outside South Africa. Clearly, the ideas underlying his work are not specifically South African ${ }^{8}$ but rather flow from a certain reading of the tradition of liberal constitutionalism; therefore, the potential appeal of the culture of justification extends to other liberal democracies as well. ${ }^{9}$ This quality, in addition to its intuitive power, explains why it has become such a widely discussed concept since Mureinik's first invocation of it. This discussion has various facets. Prominently among them is the question of the appropriate standard of review in administrative law: since a consensus quickly emerged that the proper doctrine to assess the justifiability of an act is proportionality (more on this below), the question arose of whether other standards of review, and in particular Wednesbury reasonableness, should be replaced with proportionality; this debate is still ongoing. ${ }^{10}$

\footnotetext{
${ }^{8}$ On the South African discussion, see Johan van der Walt and Henk Botha, 'Democracy and Rights in South Africa: Beyond a Constitutional Culture of Justification', 7 (2000) Constellations 341.

9 See, for example, Grant Hooper, 'The Rise of Judicial Power in Australia: Is There Now a Culture of Justification?', 41 (2015) Monash University Law Review 102.

${ }^{10}$ See, in particular, David Dyzenhaus, Murray Hunt, and Michael Taggart, 'The Principle of Legality in Administrative Law: Internationalisation as Constitutionalisation', 1 (2001) Oxford University Commonwealth Law Journal 5, 29-32; Michael Taggart, 'Reinventing Administrative Law', in Bamforth
} 
On a constitutional level, Cohen-Eliya and Porat have put forward the striking claim that the culture of justification is now the emerging global legal culture'. ${ }^{11}$ They support this by pointing to a number of developments in the constitutional law of various liberal democracies. First and foremost, the global success of the principle of proportionality in human and constitutional rights law is an indicator of the growing influence of the culture of justification. Proportionality is a doctrine used in order to assess whether a limitation of a fundamental right is justified. Thus, human and constitutional rights law usually adopts the following two stage structure. At the first stage, the court asks whether the act in question has limited a fundamental right. If so, then at the second stage it examines whether this limitation is justified, and the test used to establish this is proportionality. The proportionality test has four steps: (1) legitimate goal (where the goal of the policy and its legitimacy have to be established); (2) suitability or rational connection (the question being whether the policy contributes to the achievement of the goal; in other words, whether there is a rational connection between the policy and the goal); (3) necessity (which examines whether there is a less restrictive but equally effective alternative); and (4) balancing (where the seriousness of the interference is balanced against the importance of the competing right or interest). Cohen-Eliya and Porat claim that proportionality is the tool used to assess the justifiability of state action: 'At its core, [the culture of justification] requires that the government provide substantive justification for all of its actions, in that it must show the rationality and reasonableness of those actions and the tradeoffs they necessarily entail - in other words, the proportionality of its actions. ${ }^{\prime 2}$

and Leyland (eds.), Public Law in a Multi-Layered Constitution (Hart Publishing, 2003), 311, 332-334; Thomas Poole, 'The Reformation of English Administrative Law', 68 (2009) Cambridge Law Journal 142; David Dyzenhaus, 'Proportionality and Deference in a Culture of Justification', in Huscroft, Miller, and Webber, Proportionality and the Rule of Law: Rights, Reasoning, Justification (Cambridge University Press, 2014), 234; Mark Elliott, 'From Bifurcation to Calibration: Twin-Track Deference and the Culture of Justification', in Wilberg and Elliott, The Scope and Intensity of Substantive Review: Traversing Taggart's Rainbow (Hart Publishing, 2015), ch. 4. For an overview of the different doctrinal approaches, see Thomas Poole and Sangeeta Shah, 'A Very Successful Action? Historical Wrongs at Common Law', LSE Law, Society and Economy Working Papers 17/2016 (available at https://papers.ssrn.com/sol3/papers.cfm?abstract_id=2869840), 17-20.

${ }^{11}$ Cohen-Eliya and Porat (above $n$ 1), 7.

12 Ibid., 7. On a normative level, Cohen-Eliya and Porat (ibid., ch. 4) prefer a different approach to justification, which they label the 'intent-based model' (as opposed to proportionality, which in their view represents an 'impact-based model'). The intent-based model focuses on identifying the presence of impermissible, and therefore 'excluded', intentions or motives (for example, dislike of a certain group) in the decision-making process, whereas the impact-based model (in their view, proportionality) is about assessing whether the act in question is justifiable in terms of its impact, that is, if it optimises certain goods or values. Cohen-Eliya's and Porat's equation of proportionality with the impact-based model is, however, unfortunate because proportionality necessarily incorporates both elements - intent and impact - into its structure. At the first stage of the test, the legitimacy of the goal is examined; this corresponds to questioning what they call 'intent'. In particular, moralistic or paternalistic goals (or 'intents') are considered impermissible and will therefore be excluded from the further analysis (on the centrality of excluded reasons arguments for proportionality analysis see Mattias Kumm, 'Political Liberalism and the Structure of Rights: On the Place and Limits of the 
The spread of proportionality is thus an indicator of the shift towards a culture of justification. However, as pointed out above, the culture of justification claims not only that infringements of rights have to be justified, it insists on the justification of any state action which affects a person. Cohen-Eliya and Porat observe that courts have relied on two strategies to achieve this. First, there is a trend towards the removal of barriers to judicial review (and thus the avoidance of legal 'black holes'). Examples of this include the weakening or abolishing of 'political question' doctrines and the relaxation of the requirements for standing. ${ }^{13}$ Second, they observe an expansion of the scope of (prima facie) rights, which has the effect of subjecting more acts of the state to constitutional scrutiny and therefore strengthening the culture of justification. ${ }^{14}$ The most extreme example of this global trend is the German Federal Constitutional Court's approach to the interpretation of Article 2(1) of the Basic Law, which protects everyone's right to freely develop his personality. The Court decided that this has to be understood as guaranteeing a right to freedom of action (to do as one pleases). ${ }^{15}$ The effect of this broad reading is that any state act which limits a person's ability to do as he pleases interferes with a constitutional right and will therefore be subjected to proportionality analysis, in other words: it will require the justification that the culture of justification demands.

Proportionality Requirement', in Pavlakos (ed.), Law, Rights and Discourse: The Legal Philosophy of Robert Alexy (Hart, 2007), 131, 142-148; see further Kai Möller, The Global Model of Constitutional Rights (Oxford University Press, 2012), 183-193). The fourth stage of the proportionality assessment - the balancing stage - can be taken to represent what Cohen-Eliya and Porat call 'impact' in that here the impact of the policy on the right-holder and the competing public interest are weighed against each other. This utilisation of both intent and impact is normatively appropriate in a culture of justification; this can be explained in the following way. In a culture of justification, the role of proportionality is to assess whether a law or act is justifiable. Proportionality goes about this by first identifying those considerations which can properly be invoked in order to justify an act and excluding those which are impermissible (legitimate goal stage), in order to then ask whether the appropriate considerations do in fact justify the law or act in question (suitability, necessity, and, in particular, balancing stage). Thus, it is precisely the interplay between excluding impermissible considerations and then assessing the strength of the legitimate considerations that generates the appeal of a well-conducted proportionality analysis. For example, a properly conducted proportionality assessment of a prohibition on assisted suicide would exclude at the legitimate goal stage any goals relating to religious convictions about the sanctity of life, but it would regard as permissible the goal of preventing abuse of vulnerable people; at the final three stages of the test the strength of this reason would then be assessed in order to determine whether a prohibition of assisted suicide is justifiable in light of this permissible consideration. For a more comprehensive analysis of Cohen-Eliya's and Porat's view on this issue, see Kai Möller, 'Authority and Intent in U.S. Constitutional Culture', 10 (2014) Jerusalem Review of Legal Studies 123 (123-7); for Cohen Eliya's and Porat's reply see 'Reply to Commentators on Proportionality and Constitutional Culture', 10 (2014) Jerusalem Review of Legal Studies 159 (170-3).

\footnotetext{
${ }^{13}$ Ibid., 113-117.

${ }^{14}$ Ibid., 119.

${ }^{15}$ BVerfGE 6, 32 (1957) (Elfes).
} 
Cohen-Eliya and Porat make two further observations in support of their claim that the culture of justification is now globally dominant. First, they observe a trend to award relatively little weight to the text of the constitution. Rather than applying a conventional set of interpretative methods to the constitutional text, courts tend to read constitutions in a way that requires or allows them to focus on the substantive justifiability of the act in question; ${ }^{16}$ this, again, is evidence of a move towards a culture of justification and corresponds to Mureinik's insistence that the constitution ought to be interpreted in light of what he regards as its purpose, namely to bring about a culture of justification. Second, in a more cursory way they claim that in a culture of justification the judiciary is regarded, in an 'optimistic' fashion, as an institution which possesses the ability to distinguish right from wrong and which can impose standards of rationality and reasonableness on other political actors, ${ }^{17}$ and that a culture of justification tends to promote what they refer to as a 'substantive' or 'deliberative' conception of democracy which focuses not on the demands or claims of certain interest groups but rather on a collaborative effort to work out what is required by public reason. ${ }^{18}$

\section{The right to justification}

The shift towards a culture of justification is a development that requires not only an empirically, culturally and historically informed analysis but also, crucially, a moral one. Any moral defence of the culture of justification amounts to making a claim to the effect that every person is entitled to what Rainer Forst has called (in a different context, as we will see) the 'right to justification'. This section looks at Forst's and Mattias Kumm's invocation of that idea. As we will see, there are important lessons to be learned from both authors, who however stop short of providing a comprehensive moral account of the culture of justification.

\section{Forst and the basic human right to justification}

The German philosopher Rainer Forst is well known for his view that there is a basic right to justification which grounds human rights. This sounds like a straightforward fit with the culture of justification, but as this section will show, the situation is more complex and ambiguous. However, his central idea, that is, the idea of humans as justificatory beings, will indeed be a building block in justifying the right to justification, as will become clear further below.

Forst's starting point is a particular view of human beings as justificatory beings: they 'not only have the ability to justify or take responsibility for their beliefs and actions by giving

\footnotetext{
${ }^{16}$ Cohen-Eliya and Porat (above n 1), 119-120.

${ }^{17}$ Ibid., 120-121.

${ }^{18}$ Ibid., 121-122.
} 
reasons to others, but in certain contexts they see this as a duty and expect that others will do the same.' ${ }^{19}$ Their basic right to justification flows from this quality and in turn grounds human rights.

'The normative basis for a conception of human rights is the right of every moral person to be respected as someone who has a moral right to justification ... This means that ... political or social structures or laws have to be based on or (at least) to be compatible with moral norms applicable to them and must be justifiable within appropriate legal and political structures (and practices) of justification. ${ }^{20}$

This statement can plausibly be read in the following way: human beings have human rights to live under morally justifiable legal and political (and one may add: constitutional) structures (for example, they have a human right to live in a democracy that respects the rule of law, the separation of powers, etc); and additionally their right to justification requires that any law that is applicable to them be morally justifiable. While in a way this view may be regarded as radical because it draws very demanding content from the concept of human rights, there is a moral clarity to it that strikes me as intuitively powerful: taking persons seriously as justificatory agents requires subjecting them to the coercive power of the law only when there is an adequate moral justification for this.

There is, however, some evidence that this is not what Forst has in mind. He explains that the construction of human rights

'leads to a list of those basic rights that persons who respect one another as equals with rights to justification cannot properly deny each other. That kind of list ... expresses basic standards of respect that must be secured in the form of basic rights, given that this form has proven historically to be the appropriate one for safeguarding individual claims and entitlements. ${ }^{21}$

This indicates that for him human rights play a role that is more limited than it is under the culture of justification; under the latter a 'list' of rights is not needed (or, in any case, not central) because the culture of justification insists that all acts of the state need to be justified, not just those which interfere with one or more of the rights included in a 'list' of rights. So Forst's view seems to be that in order to create a justified constitutional structure, it may be sufficient to guarantee the widely endorsed values of democracy, the rule of law, and the separation of powers as well as a bill ('list') of rights that protects certain individual claims and entitlements that, as history teaches us, require this special protection.

Kyritsis has recently made a similar point with regard to the proper interpretation of Forst's idea of the right to justification. He argues that we may concede that the right to justification requires that laws that affect a person be morally justifiable, but this does not require a justification for every individual law; rather, there is 'an equally plausible alternative, namely that the demand for an adequate justification of the state's coercive power is addressed further upstream, long before we get into concrete conflicts. It is resolved by our

\footnotetext{
${ }^{19}$ Rainer Forst, The Right to Justification (Columbia University Press, 2011), 1.

${ }^{20}$ Rainer Forst, 'The Justification of Human Rights and the Basic Right to Justification: A Reflexive Approach', 120 (2010) Ethics 711, 734.

${ }^{21}$ Ibid., 735.
} 
joining the political condition.' 22 Put differently, a law that burdens a person is justified by 'political legitimacy', which for Kyritsis 'requires that the political order as a whole is structured such that it reliably and systematically promotes justice' ${ }^{23}$

Kyritsis' point nicely captures what I suspect is the most powerful objection to the culture of justification: that it is not clear why a substantive justification is needed for all laws, as opposed to a procedural one that stresses that a law can be justified by virtue of having been passed in a democratic (majoritarian) way. This is the crux of the moral case for the culture of justification, and Forst's writings do not (directly) help us resolve it.

\section{Kumm and the conditions of democracy}

Mattias Kumm has argued that proportionality-based judicial review institutionalises a fundamental 'right to justification'. His diagnosis of the current state of human and constitutional rights law will ring familiar in light of the above remarks on the culture of justification. He observes that the structure of human and constitutional rights law tends to follow a two stage approach, with a very broad scope of rights at the first stage, and a proportionality test at the second stage. He claims that the proportionality test institutionalises a test of public reason: 'The proportionality test merely provides a structure for the demonstrable justification of an act in terms of reasons that are appropriate in a liberal democracy. Or to put it another way: it provides a structure for the justification of an act in terms of public reason.' ${ }^{24}$ The combined effect of the broad scope of rights at the first stage and this kind of proportionality test is that 'the language of human and constitutional rights is used to subject practically all acts of public authorities that affect the interests of individuals to ... proportionality review and thus to the test of public reason. ${ }^{25}$ This, of course, is very close to what Mureinik had called the culture of justification.

Kumm then offers a moral defence of the right to justification that centres on the legitimacy conditions of democracy. He argues that the starting point of thinking about democracy should not be 'majorities' but rather 'consent': the consent of the governed. But since consent cannot usually be achieved in the real world, a surrogate is required. The conventional view would be that the appropriate surrogate lies in the idea of majority-voting and that therefore political decision-making is legitimate if the policy in question has been passed by a majority. Kumm disagrees: he says that we need two criteria which need to be cumulatively fulfilled for an act to be legitimate: first, there must be majoritarian decision-making based on an equal right to vote; and second, there must be an outcome-oriented test, namely that the outcome

\footnotetext{
22 Dimitrios Kyritsis, Where Our Protection Lies (Oxford University Press, 2017), 66.

${ }^{23}$ Ibid.

${ }^{24}$ Mattias Kumm, 'The Idea of Socratic Contestation and the Right to Justification: The Point of RightsBased Proportionality Review', 4 (2010) Law \& Ethics of Human Rights 141, 150.

25 Ibid., 152.
} 
'must plausibly qualify as a collective judgment of reason about what the commitment to rights of citizens translates into under the concrete circumstances addressed by the legislation. Even if it is not necessary for everyone to actually agree with the results, the result must be justifiable in terms that those who disagree with it might reasonably accept.'26

This reasoning is structurally similar to Ronald Dworkin's well known defence of judicial review. Dworkin had argued that collective decision making is legitimate only when it respects the conditions of political community, and hence it must treat every member of the community as an equal partner, giving him a voice in the decision, a stake in it, and independence from it. ${ }^{27}$ In a structurally parallel but substantively different fashion, Kumm argues that collective decision making is about the collective resolution of reasonable disagreements about questions of policy. Thus, to be legitimate, a collective decision must choose one of the reasonable policy options; if it chooses an unreasonable one, it is acting illegitimately:

'Even those left worst off and most heavily burdened by legislation must be conceivable as free and equal partners in a joint enterprise of law-giving. Those burdened by legislation must be able to see themselves not only as losers of a political battle dominated by the victorious side (ah, the spoils of victory!), they must be able to interpret the legislative act as a reasonable attempt to specify what citizens - all citizens, including those on the losing side - owe to each other as free and equals.' ${ }^{28}$

As this shows, Kumm attaches special significance to the idea of reasonable disagreement. His work is partly a response to Jeremy Waldron who argues that because there will usually be disagreement about questions of rights, and because this disagreement will usually be reasonable, it should be resolved by a democratic vote in parliament, as opposed to by judicial decision. ${ }^{29} \mathrm{Kumm}$ 's response is that if the disagreement is really reasonable, the legislature's decision indeed ought to stand, but that courts have a role to play in striking down unreasonable policies.

The duty on the part of the community to treat every member of the community as a free and equal partner corresponds to the right of each member of a community to insist that a law that burdens him be a reasonable attempt of specifying his rights and duties; in other words: that it be justifiable to him, which is assessed with the help of the proportionality test. For Kumm the 'right to contest' is as fundamental as the right to vote because both rights reflect the two basic conditions of democracy: majority voting (which translates into the right to vote) and justifiability of a policy to every individual person (which translates into the right to contest/justification) ${ }^{30}$

\footnotetext{
${ }^{26}$ Ibid., 168, emphases in the original.

27 Ronald Dworkin, Freedom's Law: The Moral Reading of the American Constitution (Harvard University Press, 1996), 24.

${ }^{28}$ Kumm (above n 24), 168.

${ }^{29}$ Jeremy Waldron, 'The Core of the Case Against Judicial Review', 115 (2005-6) Yale Law Journal 1346; Waldron, Law and Disagreement (Oxford University Press, 1999), Part III.

${ }^{30}$ Kumm (above n 24), 170-171.
} 
The idea of reasonable disagreement, which features prominently in Kumm's defence of the right to justification, will be discussed in the next section. At this point, my concern is a certain inbuilt limitation to the breadth of his theory. Kumm's focus is on the relationship between democracy and human/constitutional rights, and accordingly he develops his account of the right to justification out of an analysis of the proper meaning of democracy. The downside of this argumentative route is that the full potential of the idea of a right to justification is not realised. First, while it is of course true that the core case of any defence of constitutional judicial review must be judicial review of primary legislation (because here the potential conflict with the value of democracy presents itself most starkly), the right to justification applies to all state action, including acts of the executive and judicial decisions. It seems implausible, however, to justify the right to justification with regard to actors other than the legislature on the basis of a proper understanding of democracy. Rather, and this leads to my second point, it would seem that a basic right to justification must flow not from the value of democracy but from a fundamental status of each person as a justificatory agent. So the order of the argument must be that the foundational status of a person is his or her status as a justificatory agent, which in turn necessitates a certain conception of democracy and human rights/judicial review. Fleshing this out in more detail will be the work of the next section.

\section{Justifying the culture of justification}

The previous section has shown that Forst's work on the right to justification does not without modification lend itself to justifying the culture of justification, and that Kumm's work on the conditions of democracy is too narrow in its focus when it derives the right to justification from the value of democracy. This section builds on these two thinkers' work and proposes an account of the legitimacy of state action that centres on Forst's idea of the status of persons as justificatory agents and Kumm's invocation of the idea of reasonable disagreement. It argues that under conditions of reasonable disagreement, the status of persons as justificatory agents requires that any act that burdens them be substantively justifiable to them, and that the judicial protection of the right to justification is required as a matter of principle.

\section{Human beings as justificatory beings}

Any attempted justification of the culture of justification must start with Forst's idea of human beings as justificatory beings, that is, beings that not only have the ability to offer and receive reasons but that have a basic right to justification. And indeed, this idea must be correct (and is widely shared). The problem with it lies in the question, pointed out by Kyritsis, ${ }^{31}$ whether the right to justification requires in all cases a substantive justification, as

\footnotetext{
${ }^{31}$ See above $\mathrm{n} 22$ and accompanying text.
} 
the culture of justification would have it, or whether ordinarily a procedural justification - in the case of primary legislation this would be democratic voting - might suffice.

\section{Justification under conditions of reasonable disagreement}

I believe that the solution to this problem - procedural or substantive justification - lies in the idea and relevance of reasonable disagreement. This concept goes back to John Rawls, who had posed the following question: 'Why does not our conscientious attempt to reason with one another lead to reasonable agreement?'32 To answer it, he claimed that the sources of reasonable disagreement (which he calls 'the burdens of judgment') are 'the many hazards involved in the correct (and conscientious) exercise of our powers of reason and judgment in the ordinary course of political life'. ${ }^{33}$ This led him to conclude that 'many of our most important judgments are made under conditions where it is not to be expected that conscientious persons with full powers of reason, even after free discussion, will arrive at the same conclusion. ${ }^{34}$

To demonstrate the centrality of the idea of reasonable disagreement for an assessment of the moral appeal of the culture of justification, let us consider two theoretical positions with regard to the role of reasonable disagreement in politics. According to the first (which I call position A), the notion of reasonable disagreement does not do much work in the sphere of political morality. Rather, under position A the relevant categories are simply right and wrong. For example, when the legislature debates a law that changes the economic policy of the country, an adherent of position A scrutinising this policy would come to the conclusion that this policy is either right or wrong: if it is right, it deserves to be passed, and if it is wrong, its passing would be, all things equal, a moral mistake. Of course, further distinctions can be made within the category of wrong policies: the range might be from 'mildly wrong' to 'catastrophically wrong'. But those further distinctions simply try to find a label for the gravity of the mistake made by the legislature; no further significance is attached to them.

Under this framework, the culture of justification is morally indefensible. Remember that the culture of justification demands that any law that places a burden on a person be justifiable, and that the assessment of a law's justifiability is carried out by the courts. In a moral universe where the relevant categories are right and wrong (and there is no, or little, room for that middle space of 'wrong but reasonable'), the courts, when examining the policy,

\footnotetext{
32 John Rawls, Political Liberalism (Columbia University Press, 1993), 55.

33 Ibid., 55-56.

${ }^{34}$ Ibid., 58. In this passage, Rawls had in mind disagreements about the good; but, as Waldron has pointed out, the idea applies to disagreements about justice as well. See Waldron, 'Deliberation, Disagreement, and Voting', in Koh and Slye, Deliberative Democracy and Human Rights (Yale University Press, 1999), 210, 218 and Waldron, Law and Disagreement (Oxford University Press, 1999), ch. 7. For a comprehensive discussion of the idea of reasonable disagreement, see Christopher McMahon, Reasonable Disagreement: A Theory of Political Morality (Cambridge University Press, 2009).
} 
would only have the binary choice of either concluding that the policy was right - therefore upholding it as justifiable - or concluding that it was morally wrong - which would mean that it was unjustifiable and should be struck down. This implies that in this world the democratically elected legislature would be overruled by the courts whenever the courts came to the conclusion that the policy was not the best possible one, and this is plainly incompatible with the idea of democracy.

Before moving on to consider position B (which endorses the existence and relevance of reasonable disagreement), let me offer my reasons why I am not impressed by position A. It offers no conceptual space for a distinction that we often make in political discussions: the distinction between a policy which we think is wrong but nevertheless reasonable, and an unreasonable policy. In the former case, we may strongly disagree with the policy - possibly considering it to be unjust or the consequences it is likely to bring about to be very harmful but there is a sense of respect for the decision-maker because while we disagree with her decision, we do acknowledge that she did her job. By way of contrast, if we regard the decision as unreasonable, then the decision-maker has not done what she was elected or appointed to do, namely to govern the country (at least) reasonably. This difference matters; therefore, our conceptual apparatus should acknowledge it. ${ }^{35}$

The point can be pushed further and it can be argued that our commitment to democracy is on much firmer ground if we acknowledge the frequent presence and relevance of reasonable disagreement. Imagine there are two competing policy proposals to deal with a certain issue. Under the framework of position A, at most one of them can be right and the other will be wrong. This makes it difficult (though not necessarily impossible) to justify why the choice between the two proposals should be made by way of majority voting: it seems that the mere fact of voting cannot lend a wrong policy the gloss of legitimacy and

\footnotetext{
35 This paper cannot provide a comprehensive theory of reasonable disagreement; rather, it claims that its existence and relevance should be acknowledged because the alternative (position A) would be unappealing. There remains a considerable theoretical gap in our understanding of reasonable disagreement, especially with regard to the criteria that should be used to determine whether a specific act or policy is reasonable or not; and additionally, there will be reasonable disagreement about the limits of the reasonable (on this point see Kumm (above n 24), 170, fn. 56). An example to illustrate this point is the well-known controversy about whether torture can be justified in the 'ticking bomb' scenario. Many would hold that the structure of the reasonable requires what I would loosely call a commitment to human dignity which makes torture not only wrong but even unreasonable in all circumstances; this is the view that by and large is taken by human and constitutional rights law (which prohibits torture absolutely, and therefore accepts no room for reasonable disagreement and, correspondingly, majoritarian decision-making with regard to torture). But others will disagree and claim that torture may not only be reasonable but in fact the right thing to do in certain circumstances. So the same act will be considered to be the best possible policy (the 'one right answer') by some and outside even the realm of the reasonable by others. The example shows that from a philosophical perspective there is the need to develop a better understanding of the meaning and structure of reasonableness. It should also be noted, though, that courts are not particularly bothered by this gap in our theoretical understanding of reasonableness; judges using the proportionality method have developed a finely tuned sense of the borders between reasonable (proportionate) and unreasonable (disproportionate) policies.
} 
that therefore truth, rather than majorities, should decide about which policy is adopted. By way of contrast, if the two policy proposals are both reasonable, then there is meaningful space for both a controversial discussion and a final vote at the end of the process. As Waldron puts it:

'I think we should start from a sense that there is likely to be a diversity of impartial opinions about justice or the good, and that consensus is not ordinarily to be expected on the subject matter of politics ... I want ... to call for the development of a theory of democracy that makes voting the natural culmination of deliberation, rather than an indication that deliberation has in some sense been inadequate. ${ }^{\prime 36}$

A third and final reason why we should be hesitant to disregard the role of reasonable disagreement is that courts around the world routinely rely on a 'middle space' between right and wrong: they routinely stress that their job is not to second-guess the wisdom of the original decision-maker's decision and that their role is correspondingly more limited. ${ }^{37}$ This means that they maintain that there must a meaningful 'middle space' between rightness and wrongness: there must be the possibility for them to say: 'We are not deciding here whether this policy is right or wrong. But we are deciding whether it is justifiable, and this is a different standard.' It would seem that the only coherent 'middle space' lies in the idea of reasonableness: ${ }^{38}$ this concept points precisely to the possibility of a view that may not be right while simultaneously being justifiable. ${ }^{39}$

In light of this, let us consider the second theoretical position - position B -, which awards a prominent place to the idea of reasonable disagreement. Thus, this approach initially makes a distinction not between right and wrong but between reasonable and unreasonable; the

${ }^{36}$ Jeremy Waldron, 'Deliberation, Disagreement, and Voting' (above n 34), 218.
${ }^{37}$ See Kai Möller (above n 12), 200-202 with various examples from the case law.

38 This should not be confused with 'Wednesbury reasonableness', the standard of review used in English administrative law; rather it is a concept of reasonableness as used in moral and political philosophy. This is not the place to investigate the relationship between 'real' reasonableness and Wednesbury reasonableness, but it is probably largely uncontroversial (as well as correct) to say that Wednesbury reasonableness as traditionally applied amounts to something akin to reasonableness combined with considerable additional deference; thus, this kind of Wednesbury reasonableness is not sufficient in a culture of justification. The doctrinal test that reflects the necessity to separate reasonable from unreasonable laws and acts is, of course, proportionality. The structured nature of the proportionality test with its four separate stages lends itself more easily to a more searching form of review than the unstructured Wednesbury test. However, it is also important to note that this difference between Wednesbury reasonableness and proportionality is not a matter of conceptual truth but simply reflects how the two doctrines have come to be understood in legal practice: the degree of deference that courts use when they apply Wednesbury reasonableness or proportionality is flexible; and it should be noted that proportionality is often justifiably applied with a degree of deference as well (on this point see below 3.b).

39 Dyzenhaus makes a substantively similar claim, without however relying on the notion of reasonable disagreement: '[The administrative state's] decisions should survive review as long as they are shown by the reasons provided to be justifiable, rather than because the conclusion reached by the body happens to coincide with the conclusion that the judge would have considered correct without the benefit of engagement with the administrative body's reasoning. The culture of justification delineates and enforces the separation of powers.' (Dyzenhaus above n 10 at 255). 
category of reasonable then includes the 'right' (as in, the 'best possible') and 'wrong' ('not the best possible but still reasonable') decisions. ${ }^{40}$

Since this approach draws a distinction between reasonable and unreasonable, it is, contrary to approach A, compatible with the idea of a culture of justification. A proponent of approach $B$ can maintain that any act of the state needs to be justifiable and that the courts should enforce this: justifiability, for approach B, means that the policy must be reasonable, and this creates no problems for democracy because it leaves enough leeway for democratic bodies to choose between different (reasonable) policies.

This does not yet answer the question, posed at the end of the previous section, of whether the right to justification really demands a substantive justification (as the culture of justification would have it). The question is whether it is appealing to maintain that a policy which is unreasonable can be justified to a person burdened by it by virtue of having been passed by a democratically elected legislature. I can see no reason why this should be so. The job of the legislature is to pass policies that are at least reasonable, whereas it fails to do its job when it passes unreasonable policies. There is simply no moral reason to value the freedom of the legislature (and, by implication, the freedom of the voters whom it represents) to pass laws that are not even reasonable when it could just as well have passed a reasonable law. It follows that under approach $\mathrm{B}$, which rightly awards a prominent place to the notion of reasonable disagreement, the right to justification requires that any policy which places a burden on someone be substantively (reasonably) justifiable.

\section{The institutional question}

\section{a) Judicial review as a matter of principle}

The last building block of my defence of the culture of justification is the institutional issue. So far I have shown that as a matter of political morality, every person holds a right to justification which requires that any policy which places a burden on him be reasonably justifiable to him. This section shifts the discussion from morality to institutional design and asks whether the right to justification ought to be constitutionally protected and judicially enforced.

According to what strikes me as the most wide-spread approach to the issue of the relationship between moral and institutional questions, institutional design is a tool whose purpose it is to facilitate bringing about desirable outcomes. Thus, if the desirable outcome is the adequate protection of fundamental rights, then under this view judicial review is justified if it brings about a level of protection of fundamental rights that is better than under alternative institutional arrangements. A paradigmatic statement of this view can be found in Ronald Dworkin's discussion of judicial review:

\footnotetext{
${ }^{40}$ Alternatively one could speak, as Rawls does, of truth and falsity. See Rawls (above n 32), 58: 'Some conflicting reasonable judgments ... may be true, others false; conceivably, all may be false.'
} 
"I see no alternative but to use a result-driven rather than a procedure-driven standard for deciding [institutional questions]. The best institutional structure is the one best calculated to produce the best answers to the essentially moral question of what the democratic conditions actually are, and to secure stable compliance with those conditions. A host of practical considerations are relevant, and many of these may argue forcefully for allowing an elected legislature itself to decide on the moral limits of its power. But other considerations argue in the opposite direction, including the fact that legislators are vulnerable to political pressures of manifold kinds, both financial and political, so that a legislature is not the safest vehicle for protecting the rights of politically unpopular groups." 41

We can quickly see that Dworkin's, or indeed any, result-driven approach does not quite 'fit' in the case of the right to justification; this can be explained in the following way. We might say that the outcome that the right to justification wants to achieve is justifiable policies and acts, and that therefore, under a result-driven approach, the question should be whether the existence of judicial review of all state actions that burden someone is likely to lead to a state of affairs where more state action is justifiable than under alternative arrangements. From this starting point, we could then delve into a discussion of those areas and considerations where it seems likely that courts will make a contribution to the overall justifiability of policies and acts and those where this seems less likely.

What this picture misses, however, is that the right to justification properly understood cannot be seen to be exclusively concerned with the outcome or result of 'justifiable policies'. Rather, it must also insist that every person has the right to challenge any act or policy that imposes a burden on him. This follows from the conception of the person that underlies the right to justification: persons are seen as justificatory agents, that is, agents whose status allows them to challenge and demand adequate reason for any law or act that relevantly affects them. The protection of this status requires not only certain outcomes (justifiable policies) but also the availability of the corresponding procedures that allow a justificatory agent to have an independent and impartial person or body assess the justifiability of an act that burdens her; put differently, this status requires the availability of judicial review. ${ }^{42}$

The above argument is related to Alon Harel's important defence of a 'right to a hearing'. ${ }^{43}$ Harel defends judicial review as a matter of principle (and thus independently of what he calls 'instrumentalist' considerations). While his argument rests on propositions that are structurally different from the right to justification and cannot, therefore, be applied without modifications to the issue at stake in this paper, I believe that Harel's insights are even more forceful in the case of the right to justification than under the propositions that he accepts.

\footnotetext{
${ }^{41}$ Dworkin (above n 27), 34.
}

${ }^{42}$ One might object to this claim that the justificatory agent is not necessarily entitled to a judicial process, and that therefore other, non-judicial avenues of justification might be considered. In reply to this, I employ an argument parallel to Alon Harel's (whose general approach to the necessity of judicial review I discuss below) and claim that the right to justification requires that there must be an opportunity to raise grievances; these grievances must be examined and if necessary the original decision must be reconsidered. Any institution that provides this should properly considered to be a court according to the logic that 'if it walks like a duck, quacks like a duck, looks like a duck, it must be a duck'. See Alon Harel, Why Law Matters (Oxford University Press, 2014), 214.

${ }^{43}$ Harel (above n 42), ch. 6. 
His view of rights is traditional in that he assumes not a right to justification (that is, a right to be subjected only to justifiable laws and acts) but rather a number of discrete rights (such as, say, freedom of speech, freedom of religion, etc.). On this basis, he defends a right to a hearing in situations where there is a dispute about whether a particular right has been justifiably infringed or about the very existence of a particular right (a paradigmatic example of the first situation would be a law that prohibits obscene speech and therefore limits the right to freedom of speech; an example of the second scenario would be where the rightholder claims a right to an education and it is unclear whether such a right actually exists). ${ }^{4}$ So while Harel does not base his theory on any particular conception of rights, his starting point makes it clear that he does not believe in one general right to justification. ${ }^{45}$

With this in mind, let us look at his defence of a right to a hearing. With regard to the first situation (which is closer to the issue at stake here), Harel argues:

'There is ... an important link between individual rights and the right to a hearing. The existence of a prima facie right gives the right-holder a stake in that right and power over it, even when the right is justifiably overridden. The right to a hearing is grounded in the fact that people occupy a special position with respect to their rights. Rights demarcate a boundary that has to be respected, a region in which the right-holder is a master ... A determination that the right has been justifiably infringed does not nullify the privileged position of the rightholder. Instead, his privileged position is made concrete by granting the right-holder a right to a hearing. Thus, infringing the right unilaterally is wrong even when the infringement itself is justified because the right-holder is not treated as someone who has a say in the matter. ${ }^{\prime 46}$

Elsewhere, Harel speaks of the 'fingerprint' or 'moral residue' that a right leaves even if it is justifiably infringed. ${ }^{47}$ The idea is that a moral right to $X$ means not only that $X$ has to be respected but also that, if it is justifiably not respected, the right-holder is owed a hearing. Harel develops his approach largely by way of reasoning by analogy; this makes it difficult to pin down its core proposition from which the right to a hearing flows. I wonder whether his idea can be expressed in a simpler and more forceful way by recurring to the notion of people as justificatory agents: if we treat people as justificatory agents, and if we accept that they have rights - independently of whether they have a set of specific rights (traditional view) or a broad right to justification (as the culture of justification would have it) - then this means that they must be given the opportunity to demand acceptable reasons for any act that can plausibly be regarded as violating a right. Denying them this opportunity treats them, in Harel's words, 'as someone who [does not have] a say in the matter'.

\section{b) Deference in the culture of justification}

There may be a tension between the moral necessity of judicial review in a culture of justification as defended in the previous section and the occasionally limited institutional

${ }^{44}$ Ibid., 203.

45 On this point see also his 'Do Legal Rights Matter? Comments on the Global Model of Constitutional Rights', 10 (2014) Jerusalem Review of Legal Studies 187.

${ }^{46}$ Harel (above n 42), 204-205.

${ }^{47}$ Ibid., 209. 
competence of courts to carry out this review. As is widely accepted, despite their considerable institutional strengths (including independence and impartiality), courts struggle with the problem of institutional competence in some situations and in response to this problem have developed tools such as the doctrines of deference or the margin of appreciation ${ }^{48}$ that are usually integrated into the application of the proportionality test and that allow them to defer to the original decision-maker to an extent. ${ }^{49}$ The problem with deference, however, is that it may result in a court upholding a law or act as proportionate and therefore justifiable when in reality it is not. ${ }^{50}$ How does this relate to the moral necessity of protecting people's fundamental right to justification?

For a proponent of the view that judicial review is justified only to the extent that it promotes better outcomes than alternative arrangements, deference does not pose a problem; on the contrary, it is one of the tools that ensures that judges remain within their zone of competence and therefore produce decisions that will really improve the quality of rights protection. Under the view taken in this paper, the situation may seem more complicated because I argued that judicial review must exist not to improve outcomes but rather as a matter of principle. One way of dealing with this problem, albeit not a convincing one, is to deny it. Harel comes close to doing this when he writes:

The right-to-a-hearing conception dictates that individual grievances are seriously considered and evaluated, and that the institutions designed to investigate these grievances are engaged in good faith and serious moral deliberation ... [T] his conception ... maintains that courts ought to engage in serious good-faith deliberation in order to honour that right. It is unlikely that such serious good-faith deliberation fails to protect rights in an adequate manner..$^{51}$

${ }^{48}$ The doctrine of the margin of appreciation is used by the European Court of Human Rights and was introduced in the famous Handyside case, where the Court held: 'By reason of their direct and continuous contact with the vital forces of their countries, State authorities are in principle in a better position than the international judge to give an opinion on the exact content of these requirements as well as on the "necessity" of a "restriction" or "penalty" intended to meet them.' (Handyside v. United Kingdom, (1979-80) 1 E.H.R.R. 737, 753-754).

${ }^{49}$ Some scholars also discuss a second ground for deference, namely 'democratic legitimacy'; see Alan Brady, Proportionality and Deference under the UK Human Rights Act: An Institutionally Sensitive Approach (Cambridge University Press, 2012), 106. Under the approach proposed in this article, there is little or no room for deference on the grounds of democratic legitimacy because the whole point of the culture of justification is that every act by the democratic legislator needs to be substantively justifiable. But the standard applied to assess the justifiability of a law or act, namely proportionality/reasonableness, does of course leave considerable room to the democratic decisionmaker. More as a matter of conceptual clarity than as a substantive issue, I believe that it is preferable to avoid referring to the corresponding leeway that courts grant the original decision-makers as 'deference'; I would prefer to say that courts are assessing the justifiability (that is, reasonableness, proportionality) of the original decision without any deference on the grounds of democratic legitimacy.

${ }^{50}$ On this dilemma, see Alexy A Theory of Constitutional Rights (Oxford University Press, 2002), 422425.

${ }^{51}$ Harel (above n42), 211 (emphasis added). 
It is notable that in an earlier version of this passage, Harel had used the word 'inconceivable' instead of the much weaker 'unlikely' that appears in his book. ${ }^{52}$ So he seems to have softened his stance on this issue. Nevertheless, he fails to appreciate the problems involved in judicial review; while it is of course true that courts are expected to engage in serious and good faith deliberation, often the empirical basis of the policy or act in question is so complicated that the court has no choice but to defer, to an extent, to the judgment of the original decision-maker. ${ }^{53}$

I believe that deference can be reconciled with the acknowledgement of the necessity of judicial review in a straightforward way. Due deference does not offend people's right to justification for the simple reason that a person cannot have a right to a justification that provides more than what a court that looks at the issue 'with an open heart' (Harel) can be expected to deliver. Justificatory practices are human practices and therefore subject to human limitations, including human limitations with regard to epistemic issues. So a justificatory agent demanding a justification cannot expect more than other humans (that is, judges) doing their job to the best of their ability. If a court is hampered by its lack of empirical or, probably less relevant, normative understanding of the issue, then some measure of deference may be entirely appropriate. Thus, while such deference is always a reason for regret, it is compatible with the right to justification.

\section{Conclusion}

This essay has provided a moral defence of the culture of justification, that is, the idea that all laws and other acts of the state that affect a person must be substantively justifiable to that person and that individuals can rely on their constitutional rights to enforce this in court. As has become clear, the culture of justification is not only an influential idea and empirically successful practice in various liberal democracies around the world; it is also morally justifiable and indeed morally obligatory. My argument to this effect has relied on three building blocks. First and foremost, the foundation of the culture of justification lies in the fundamental status of each person as a justificatory agent, that is, an agent who has a right to justification. Second, it follows from the existence and moral relevance of reasonable disagreement that the right to justification demands that any act that affects a person be (at least) reasonable. Third, the status of persons as justificatory agents, that is, agents who can

\footnotetext{
${ }^{52}$ Alon Harel and Tsvi Kahana, 'The Easy Core Case for Judicial Review', 2 (2010) Journal of Legal Analysis 227, 247.

${ }^{53}$ Even Robert Alexy, who is otherwise a staunch defender of judicial review, has come to integrate the need for deference into his structural theory of constitutional rights by adding (in the Postscript to the English publication of A Theory of Constitutional Rights) his 'Second Law of Balancing', a formal principle according to which the more intensive an interference in a constitutional right is, the greater must be the certainty of its underlying premises. See Alexy (above n 50), 418-419. For a critical analysis of this idea, see Matthias Klatt and Johannes Schmidt, 'Epistemic Discretion in Constitutional Law', 10 (2012) International Journal of Constitutional Law 69. For a comprehensive study of this issue in the U.K. context and based on a largely Alexian framework, see Brady (above n 49).
} 
demand acceptable reasons, implies that the right to justification must be institutionally protected; in other words, the existence of judicial review is required as a matter of principle.

What follows? The moral appeal of the culture of justification gives, in particular, judges and public law scholars good reason to continue with the project that, as Cohen-Eliya and Porat have shown, is already in full swing in the liberal democratic world: the gradual transformation and reinterpretation of constitutional law and doctrines so as to make them consistent with the requirements of the culture of justification. This includes the broadening of the scope of (prima facie) rights (as championed by the German Federal Constitutional Court); the adoption of proportionality not only in constitutional but also in administrative law and the proper conceptualisation of that test as one that is concerned with distinguishing reasonable from unreasonable disagreement; the acknowledgment of the need for deference combined with the attempt to limit its breadth to cases where courts suffer from a lack of institutional competence; and more generally, the interpretation of constitutional clauses in line with the division of labour that the culture of justification recommends. This development towards a culture of justification is of great moral importance: we owe it to others and to ourselves, as justificatory agents, to make it a success. 